\title{
Electrical and structural characteristics of oxides grown from polycrystalline silicon
}

\author{
B B DIXIT, P D VYAS, W S KHOKLE, K MAHADEVAN* \\ and $H$ N ACHARYA* \\ Solid State Devices Division, Central Electronics Engineering Research Institute, Pilani \\ 333031 , India \\ * Department of Physics and Meteorology, Indian Institute of Technology, Kharagpur \\ 721302 , India.
}

\begin{abstract}
A comparative study of dielectric properties of polysilicon oxide with silicon dioxide, grown on single crystal silicon, shows that the former is more conducting due to the presence of asperites at polysilicon/ $/ \mathrm{SiO}_{2}$ interface. This paper also reports attempts made to improve the electrical properties of pulysilicon oxide by investigating the effects of oxidation temperature, polysilicon deposition temperature and doping on current field characteristics of polyoxide. Higher doping and higher oxidation temperature yield smoother interface with higher breakdown voltages and lower leakage currents. Surface morphology of polyoxide under different process conditions is also studied.
\end{abstract}

Keywords. Polycrystalline silicon; inter level insulator; polyoxide.

\section{Introduction}

Thermal oxide film grown over polysilicon, often referred to as polyoxide, is an important material for integrated circuit technology. These films are used to project layers of polysilicon gate and also as an interlevel insulator in multilevel structures. For very large scale integrated (VLSI) circuits, where thinner dielectric films and low temperature processing are used, the dielectric breakdown of the oxides grown over polysilicon is a major yield and reliability problem. Hence it is necessary to improve the electrical properties of the polyoxide taking into account the usual process conditions. The present investigation is devoted to understanding some of the physical and electrical properties of polyoxide. The effects of oxidation temperature, doping and growth temperature of polysilicon on leakage currents through the polyoxide and morphological change in polyoxide/polysilicon interface are reported.

A comparative study of dielectric properties of polysilicon oxides with oxides grown on single crystal silicon has shown that the former oxides are more conductive for a given average field (DiMaria and Kerr 1975) and have a lower breakdown strength. Electrical conduction through polyoxide involves effects of asperites present in the polysilicon/polyoxide interface, which causes higher leakage current through polyoxide (Anderson and Kerr 1977).

\section{Sample preparation and measurements}

Phosphorus doped silicon wafers $(0.8-1.2 \mathrm{ohm} \mathrm{cm})$ were thermally oxidized at $1050^{\circ} \mathrm{C}$ in dry oxygen to grow about $900 \AA$ thick silicondioxide films. Polycrystalline silicon 
Table 1. Breakdown field of samples processed under different conditions.

\begin{tabular}{|c|c|c|c|c|c|c|c|}
\hline \multirow[b]{2}{*}{ Sample } & \multirow[b]{2}{*}{ Dopant } & \multirow[b]{2}{*}{$\begin{array}{c}\text { Doping } \\
\text { temp. }\left({ }^{\circ} \mathrm{C}\right)\end{array}$} & \multirow[b]{2}{*}{$\begin{array}{l}\text { Oxidation } \\
\text { temp. }\left({ }^{\circ} \mathrm{C}\right)\end{array}$} & \multirow[b]{2}{*}{$\begin{array}{l}\text { Oxidation } \\
\text { time (min) }\end{array}$} & \multirow[b]{2}{*}{$\begin{array}{c}\text { Thickness } \\
\AA\end{array}$} & \multicolumn{2}{|c|}{ Breakdown field $(\mathrm{MV} / \mathrm{cm})$} \\
\hline & & & & & & $\begin{array}{c}\text { Poly-Si } \\
\text { negative }\end{array}$ & $\begin{array}{l}\text { Field plate } \\
\text { negative }\end{array}$ \\
\hline 1 & None & - & 850 & 500 & 525 & $5 \cdot 3$ & $5 \cdot 6$ \\
\hline 2 & None & - & 1050 & 20 & 520 & $7 \cdot 3$ & 7.2 \\
\hline 3 & Phosphorous & 900 & 850 & 20 & 500 & 6.1 & $6 \cdot 3$ \\
\hline 4 & Phosphorous & 900 & 1050 & 8 & 500 & $8 \cdot 1$ & $8 \cdot 2$ \\
\hline 5 & Phosphorous & 900 & 950 & 6 & 485 & 7.8 & 7.9 \\
\hline 6 & Phosphorous & 1000 & 950 & 4 & 520 & 8.5 & 8.4 \\
\hline 7 & Phosphorous & 900 & 1050 & 10 & 800 & 7.5 & 7.5 \\
\hline 8 & Phosphorous & 900 & 1050 & 12 & 1000 & 7.2 & $7 \cdot 2$ \\
\hline
\end{tabular}

films ( $5000 \AA)$ were deposited by atmospheric chemical vapour deposition technique. Oxide thickness and polysilicon thicknesses were measured with ellipsometer, bevelling and observation under scanning electron microscope (SEM) respectively. Some of the polysilicon films were phosphorus doped $\left(1 \times 10^{20} \mathrm{~cm}^{-3}\right)$ in a diffusion furnace. Polyoxide was then grown in dry $\mathrm{O}_{2}$ under different process conditions (table 1). With the help of aluminium metallization and photolithography, 20 mils diameter electrodes were fabricated on polyoxide and polysilicon surfaces (figure 1). I-V measurements were carried out using electrometer (Keithley 620) with positive as well as negative field polarities.

\section{Results}

\subsection{SEM study of polysilicon/polyoxide interface}

Samples were prepared for SEM examination of the polysilicon/polyoxide interface by stripping off the polyoxide in buffered hydrofluoric acid (HF). Direct evidence of the asperites, which is one of the causes of high conductivity observed in polyoxide is best illustrated in the SEM photograph (figure not shown). The flattening of asperites with increase in oxidation temperature of polysilicon is also evident (figure not shown). For phosphorus doped polysilicon samples, no asperites were found at the polysilicon/polyoxide interface (even up to $15000 \times$ magnification).

\subsection{Current field characteristics}

The current density field characteristics of polyoxide grown at two different temperatures $\left(850^{\circ} \mathrm{C}\right.$ and $\left.1050^{\circ} \mathrm{C}\right)$ over undoped polysilicon is shown in figure 2 . The leakage current density for $1050^{\circ} \mathrm{C}$ oxidized polysilicon is one decade lower than that of $850^{\circ} \mathrm{C}$ oxidized polysilicon and it remains almost constant up to $3 \mathrm{MV} / \mathrm{cm}$ field strength. The effect of doping $\left(1 \times 10^{20} \mathrm{~cm}^{-3}\right)$ of polysilicon on current density field characteristics of polyoxide is depicted in figure 3 . Here again, leakage current through polyoxide grown at higher temperature is less. It is evident from figures 2 and 3 that leakage current through polyoxide grown over doped polysilicon is about one decade less than that of 


\section{Contacts}

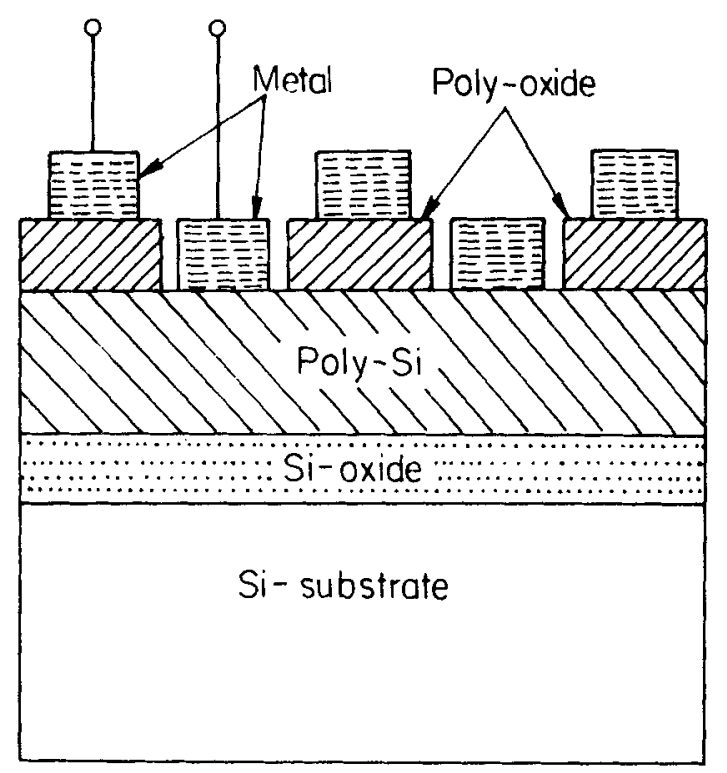

Figure 1. Final structure of mos capacitor with polyoxide as insulator.

undoped polysilicon. Leakage current density field characteristics of Heimann et al (1982) have also been plotted in figure 3. The effect of polysilicon deposition temperatures $\left(650^{\circ} \mathrm{C}\right.$ and $\left.750^{\circ} \mathrm{C}\right)$ on leakage currents through polyoxide is shown in figure 4. Higher deposition temperature gives less leakage current.

\section{Discussion}

Surface roughness of polysilicon is a direct result of intergranular oxidation of polysilicon (Suzuki et al 1977). As oxidation ensues, a stress builds up in grain boundaries due to increase in volume resulting from intergranular oxide formation. Silicon atoms creep towards midgrain regions to relieve the strain. This motion of silicon atoms depletes the amount of silicon at the grain boundaries and enhances the amount at the midgrain regions thereby elongating the grains normal to the stress.

Simultaneous with the silicon motion, oxidation also occurs and silicon is absorbed both in the grain boundaries and at midgrain regions. The net result is a thinner oxide formed at previous grain boundaries due to silicon depletion and a thicker oxide at midgrain regions that receive excess silicon atoms. At higher oxidation temperatures where oxidation is predominantly diffusion-controlled, a smoother polysilicon/polyoxide interface is produced.

In the case of oxidation of doped polysilicon, dopants segregate and precipitate in the grain boundaries. Because the dopant is electrically active within the grain, the oxidation of a grain is a surface reaction and is equivalent to oxidation of single crystal silicon. On the other hand, large amount of segregated dopant atoms in the grain 


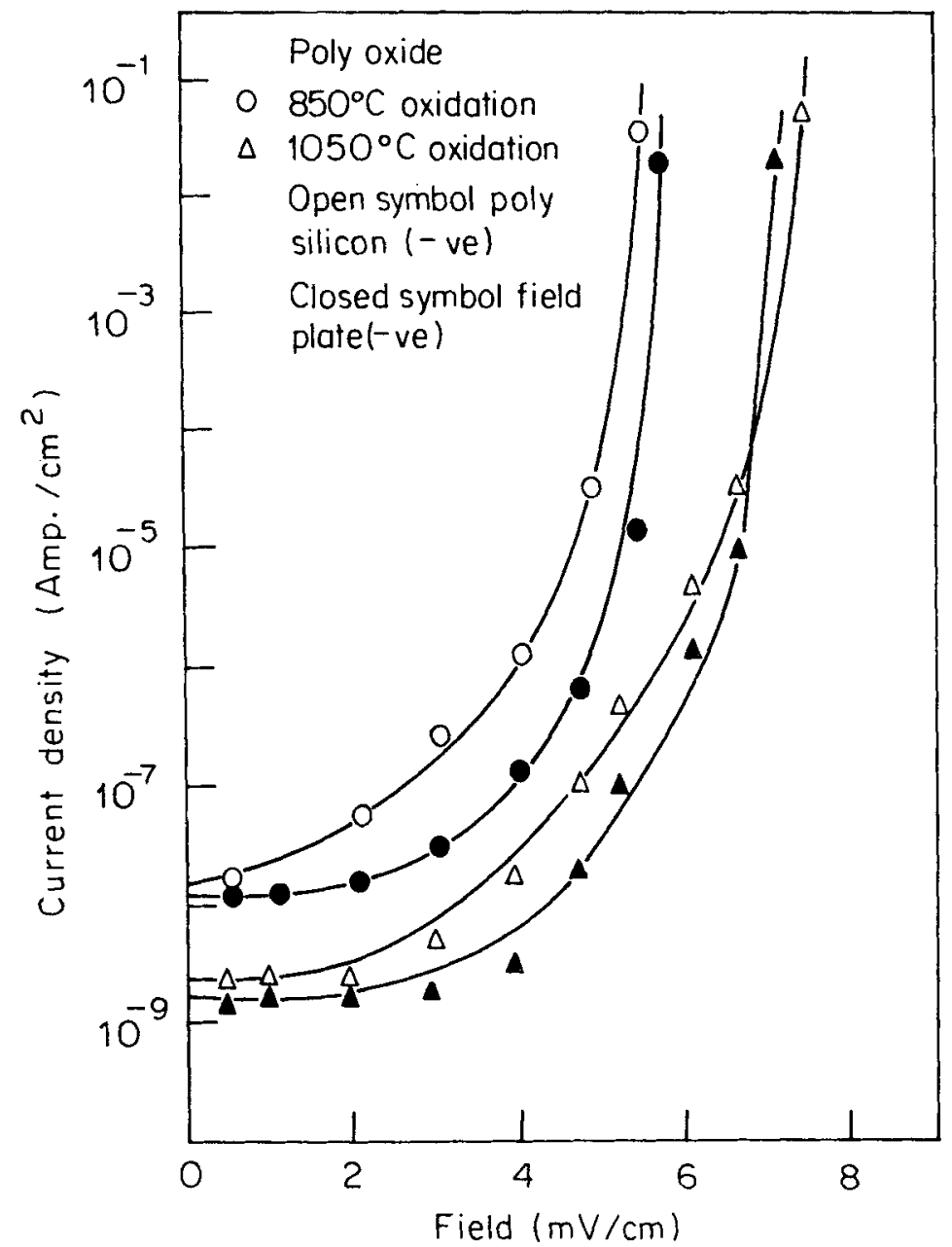

Figure 2. Current density vs field for oxides grown at two different temperatures for undoped polycrystalline silicon.

boundaries leads to an enhanced oxidation rate caused by an increase in the surface reaction rate and oxidant diffusivity through the grown $\mathrm{SiO}_{2}$ (Barnes et al 1979; Ho et al 1978).

The higher conductivity observed in oxides grown from polysilicon can be explained as follows: The electrical conduction of the polyoxides is controlled by traps in the polyoxide (Huff et al 1980; Lee and Feng 1980). Most of the electrons are trapped close to the polysilicon/polyoxide interface. The difference in the leakage currents is due to the difference in the size and quantity of protuberances and bumps at the polysilicon/polyoxide interface (Irne et al 1980; Mandurah et al 1980). These protuberances and bumps cause enhanced local electric fields which increase the injection of electrons into the polyoxide, yielding high leakage currents (Pidley 1975). Higher oxidation temperatures and doped polysilicon give smooth polysilicon/polyoxide interface. Hence leakage currents in these cases are lower (figures 2 and 3). A high temperature 


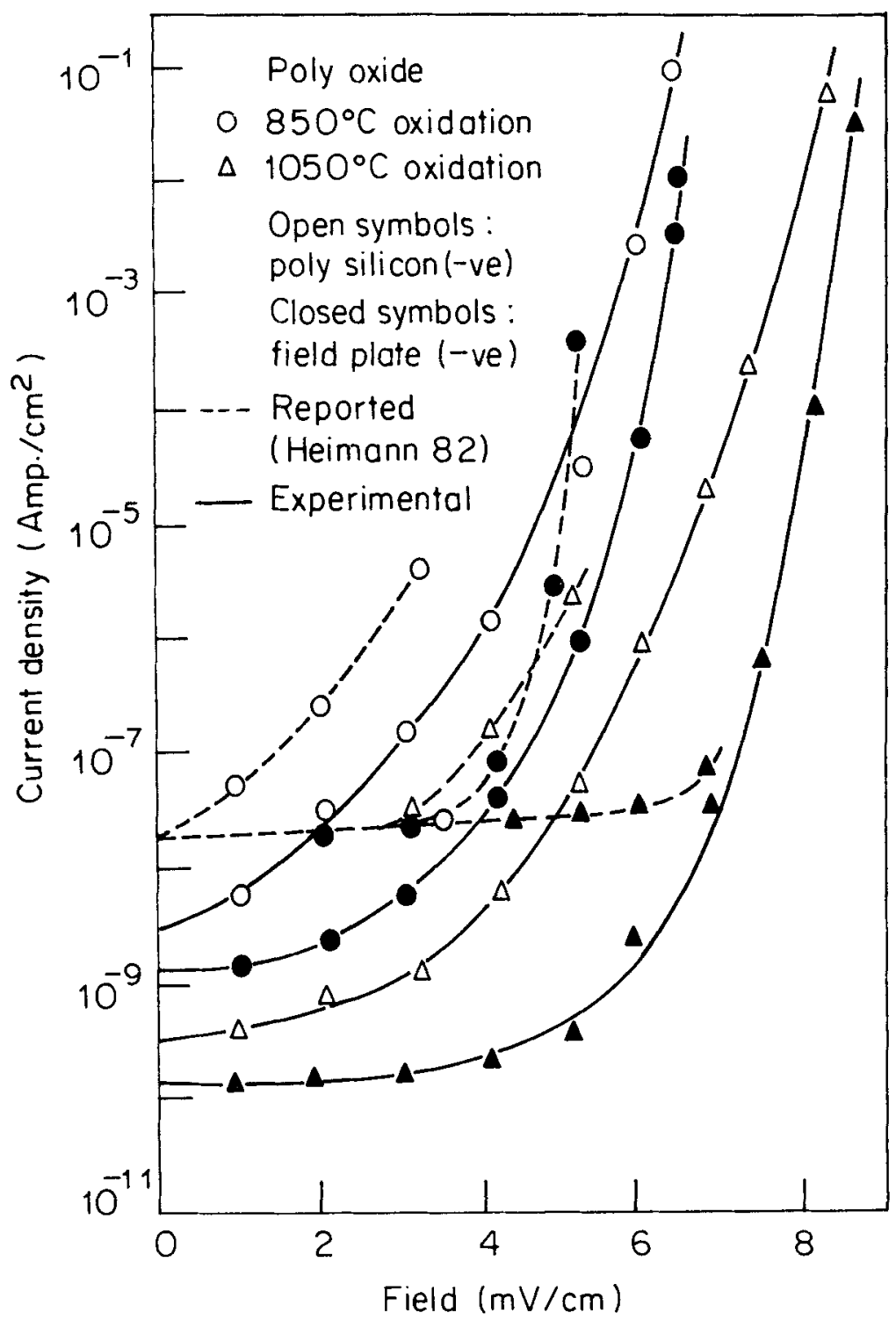

Figure 3. Current density vs field for oxides grown at two different temperatures from polysilicon doped at $900^{\circ} \mathrm{C}$.

polysilicon deposition leads to higher grain size or lesser grain boundaries and less thickness undulations and hence an improvement in leakage current and breakdown voltage.

\section{Conclusion}

A strong correlation between asperites present at polysilicon/polyoxide interface and leakage currents through polyoxides has been established. The surface morphology of polyoxides as a function of oxidation temperature for doped as well as undoped 


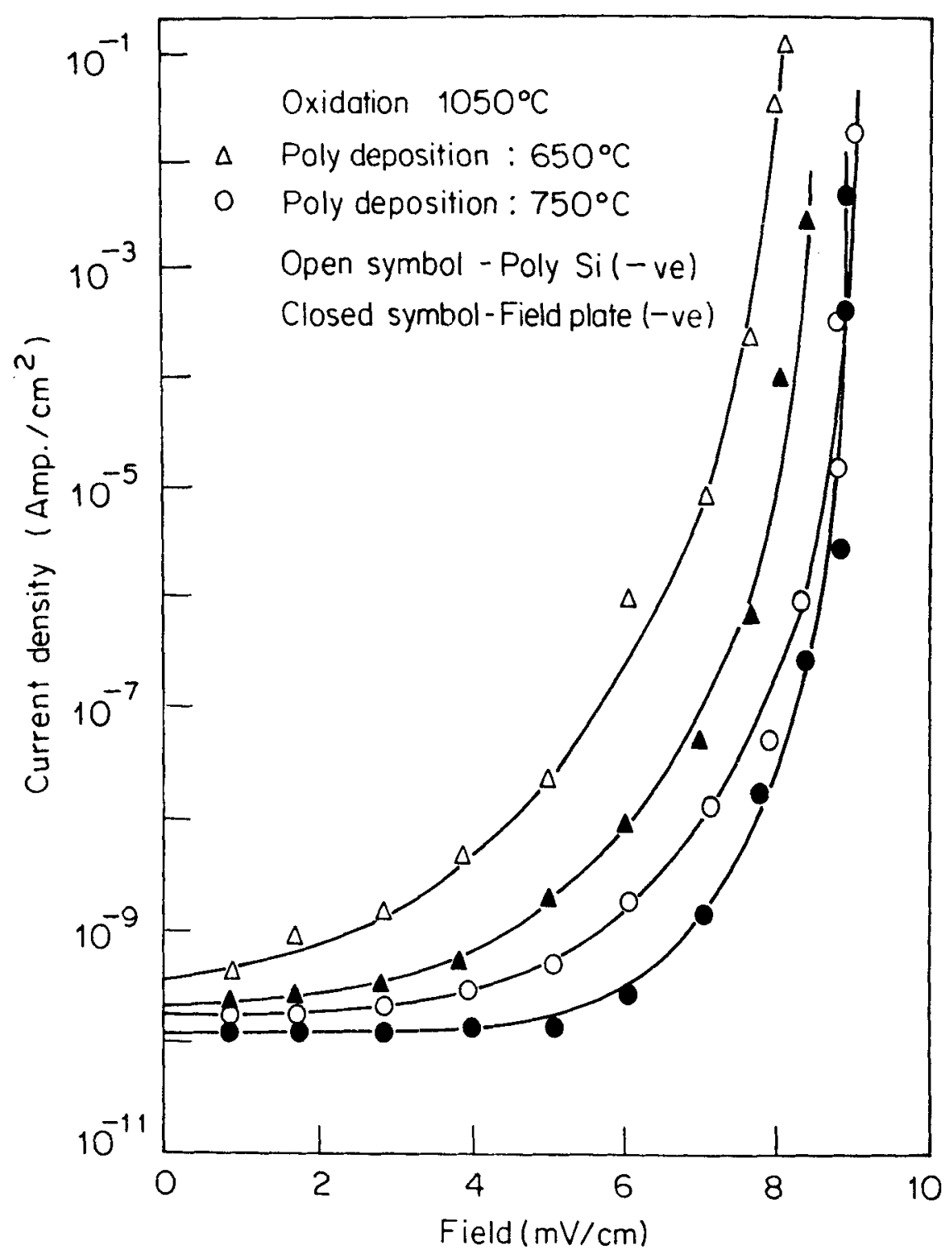

Figure 4. Current density vs field for oxides grown at $1050^{\circ} \mathrm{C}$ from polysilicon deposited at two different temperatures.

polysilicon films is examined. Higher polysilicon deposition temperature, doping and higher oxidation temperatures yield oxides with higher breakdown fields and lesser leakage currents.

\section{Acknowledgements}

Authors thank Mr P N Andhare for help in measurements and Mr D P Runthala, Mr Satish Kumar and Mr H Lal for fabrication help. 


\section{References}

Anderson R M and Kerr D R 1977 J. Appl. Phys, 484834

Barnes J J, DeBlasi J M and Deal B E 1979 J. Electrochem. Soc. 1261779

DiMaria D J and Kerr D R 1975 Appl. Phys. Lett. 27505

Heimann P A, Murarka S P and Sheng T T 1982 J. Appl. Phys. 536240

Ho C P. Plummer J D, Meindel I D and Deal B E 1978 J. Electrochem. Soc. 125665

Huff H R, Halverson R D, Chu T L and Gutermann D $1980 \mathrm{~J}$. Electrochem. Soc. 1272482

Ime E A, Tiemey E and Dong D W 1980 J. Electrochem. Soc. 127705

Lee H S and Feng C H 1980 Appl. Phys. Lett. 371080

Mandurah M M, Saraswat K C, Helms C R and Kamins T I 1980 J. Appl. Phys. 515755

Pidley B K 1975 J. Appl. Phys. 46998

Suzuki T, Minura A and Ogawa T 1977 J. Electrochem. Soc. 1241776 